\title{
O que se diz, o que se Escreve. Etnografia e trabalho de campo no sertão de Pernambuco
}

\author{
Ana Claudia Marques \& Jorge Mattar Villela \\ Universidade de São Paulo/Universidade Federal de São Carlos
}

RESUMO: A partir de certa reação negativa suscitada pela publicação de uma etnografia sobre brigas de família no sertão do Pajeú (Pernambuco), propõe-se uma abordagem da reflexividade de um trabalho antropológico, inspirada teoricamente em uma historicização do lugar do trabalho de campo e da etnografia na disciplina e empiricamente através de uma visão retrospectiva das condições específicas de realização dessa pesquisa. $\mathrm{O}$ mesmo caso produziu também efeitos de ordem pragmática, operando deslocamentos inesperados na relação entre pesquisadores e pesquisados, perceptíveis, por exemplo, no idioma utilizado nas trocas agonísticas de acusação e defesa, e que proporcionaram novas perspectivas com respeito às condições de sociabilidade que se diz descrever.

PALAVRAS-CHAVE: trabalho de campo, etnografia, reflexividade.

\section{Introdução}

Em meados de 2004, fomos surpreendidos por uma notícia profundamente perturbadora e até então insuspeita. Sua portadora foi uma leitora, até então nossa desconhecida, de Intrigas e Questôes, livro publicado por um de nós (Marques, 2002), cerca de um ano e meio antes. Seduzida pelo tema de uma das lutas de família analisada no livro, essa leitora há 
tempos vinha se dedicando a conhecer detalhes da história e de alguns de seus personagens principais, como uma sorte de hobby com que se propunha preencher algumas lacunas existenciais. Por meio de comunicação pessoal com parentes e amigos desses protagonistas, tomou conhecimento do livro pouco tempo depois de sua publicação e de certa forma partilhou com eles as distintas impressões que sua leitura proporcionou. Naquela tarde em que veio se apresentar à autora, ela declarou sua intenção de redigir a biografia de um dos principais intervenientes da questão pela qual tanto se interessara, por sugestão do próprio biografado. Sua idéia era muito interessante. Mas como negar a dificuldade em lidar com assuntos tão melindrosos quanto aqueles que justamente motivavam seu projeto? Daquela briga de família, surgiram muitos processos judiciais. E, ademais, a explicitação de papéis desempenhados por cada personagem da história certamente os comprometeria (além de os expor à curiosidade da investigação jurídico-policial) também diante de seus inimigos e, de forma mais ampla, de sua comunidade. Foi diante de tais questionamentos, para ela também inquietantes, que comentou acerca de certas reaçóes negativas que Intrigas e Questôes suscitara. Embora tenham passado despercebidas à generalidade dos leitores seus conhecidos, um deles expressou seu incontornável desagrado em razão da forma como seu pai fora retratado no livro. Seu aborrecimento foi assunto discutido entre os demais leitores que, em alguns casos, releram a passagem problemática e, segundo ela relatou, passaram a compreender seus motivos, mas trataram de minimizar sua importância. Após um período de vituperações acaloradas referidas ao livro pelo leitor descontente, o assunto fora abandonado. A portadora da notícia, observando a contrariedade que involuntariamente nos provocou, sugeriu que talvez a melhor conduta fosse abandonar o assunto a seu esquecimento.

Apesar da paralisia inicial provocada pelo choque da notícia, decidimos que era preciso tomar uma atitude que expressasse a seriedade com 
que encaramos o trabalho que desenvolvemos e o respeito que efetivamente nutrimos pelos familiares daquele leitor. $\mathrm{O}$ silêncio parecia uma opção leviana, incompatível com nossa postura diante do que fazemos e com as relações que entabulamos durante a permanência em campo. Porque realizamos o trabalho de campo na condição de um casal de pesquisadores, embora nem sempre realizando em conjunto todas as suas etapas, e porque o único contato pessoal estabelecido com pessoas próximas àquele leitor fora feito entre um irmão dele e Jorge Villela, nossa primeira iniciativa foi repetir esse contato. Dessa forma, iniciamos um diálogo extremamente penoso para nós, mas que veio a se revelar muito elucidativo. Nossos generosos interlocutores, o leitor descontente e seu irmão, trocaram várias mensagens por correio eletrônico conosco, exprimindo e argumentando seu repúdio ao texto. Os acontecimentos que se seguiram contribuíram singularmente para trazer à tona a consciência de que, e em que medida, a reflexividade de nossas pesquisas não começaram nem se encerraram na produção da etnografia. Este artigo tem por proposta identificar esse processo, cuja exposição mais crítica foi desencadeada por um acontecimento inesperado, por meio de uma visão retrospectiva das condições específicas de realização dessa pesquisa. Consideramos que a natureza e o recorte proposto ao objeto de estudo devem ter acentuado particularmente essa reflexividade, mas sugerimos que alguns dos aspectos aqui tratados sejam de fato inerentes à condição do trabalho de campo em antropologia.

\section{Antropologia, etnografia e trabalho de campo}

Muita tinta correu, desde os anos 80 , a respeito do produto do trabalho antropológico, o texto etnográfico. Em meio a muitas críticas e controvérsias internas concernentes à relação entre antropólogo e nativo, ${ }^{1}$ auto- 
Ana C. Marques \& Jorge M. Villela. O que se diz, o que se Escreve

ridade no texto antropológico (Clifford, 1983), contexto nativo e do observador (Asad, 1973), caráter fragmentar (Marcus \& Fisher, 1986) ou unidade da experiência e do produto etnográficos, caráter realista ou ficcional (Geertz, 1989[1973]; Clifford, 1986), pouco importa até que ponto em concordância com elas, transcorreram os anos de nossa formação acadêmica. Voluntariamente ou não, essa discussão fazia parte de nossa bagagem para o trabalho de campo, ainda que, conforme propôs Malinowski (1978[1922], p. 22), como instrumentos para levantar problemas antes que na qualidade de idéias preconcebidas. Difícil afirmar o quanto esse jogo discursivo influenciou os rumos da pesquisa, que não foi idealizada como uma oportunidade de testar o alcance ou a validade dessas críticas, mas é certo que elas proporcionaram um acervo fundamental de idéias que não serviram apenas no momento de retorno, mas para estabelecer a ponte entre os conceitos próximos e distantes em relação à experiência. Elas insinuaram sua presença durante a experiência de campo.

Talvez possamos caracterizar sinteticamente a empresa do trabalho de campo e de seu resultado último, o texto etnográfico, ao longo da história da antropologia do século XIX para cá como uma deriva da etnografia desde o espaço exterior do trabalho propriamente etnográfico até o seu interior mais profundo. Num primeiro momento, o material examinado pelos antropólogos ditos "de gabinete" provinha de relatos e crônicas elaborados por exploradores, missionários e funcionários coloniais localizados na posição externa e imunes ao controle dos antropólogos. Em seguida, os dados, embora ainda provenientes dos mesmos agentes, passaram a ocupar uma posição anexa ao trabalho analítico, ao mesmo tempo em que foram submetidos a seu jugo. Cursos sobre o trabalho de campo ministrados a agentes de administração colonial pelos antropólogos vitorianos e publicações como o Notes and Querries to the Inhabitants on the Uncivilized Lands (cuja primeira edição remonta a 
Revista de Antropologia, São Paulo, USP, 2005, v. 48 No 1.

1874), além do envio de questionários e da manutenção de homens em seus campos, permitiram que os dados coletados por estes últimos fossem aprimorados e dirigidos, visando preencher as lacunas existentes a respeito do conhecimento das instituiçôes e das crenças dos povos primitivos. Simultaneamente, essa primeira deriva conferiu credibilidade ao material sobre esses povos, atraindo estudiosos arredios à antropologia, desconfiados da garantia oferecida pelo material anteriormente existente. O exemplo mais célebre é, sem dúvida, Durkheim.

Em seguida, passando pelo abandono dos funcionários e missionários em proveito dos cientistas naturais na coleta de dados, escolha efetuada pelos antropólogos de gabinetes, confiantes na maior intimidade destes últimos com os métodos e procedimentos científicos, o trabalho de campo (Stocking, 1987 e 1992) e a etnografia iniciam um mergulho no fulcro mesmo da antropologia, tornando-se, por fim, guiados pela mitopoiesis de Malinowski (Stocking, 1992), no traço distintivo da profissão de antropólogo. ${ }^{2}$ A partir da introdução aos Argonautas do Pacifico Ocidental, os antropólogos ganham o traço diacrítico que extrapola seu objeto - sempre, vale lembrar, em vias de desaparição, seja ele reconhecido como os povos primitivos ou a "cultura”. Ele é agora o seu método, criativamente batizado de "observação participante".

Mas esse não seria o derradeiro avatar da experiência de campo e tampouco do texto etnográfico - um relato a respeito de todos orgânicos, seja a partir de uma parte central ou não, que desse conta precisamente destas totalidades isoladas que são as sociedades primitivas. Pois a observação participante, além de produzir o texto etnográfico como objetivo último, produz também, como uma espécie de apêndice, um texto paralelo, em tudo útil para a elaboração do escrito principal. O caderno de campo é ao mesmo tempo ferramenta, meio e condição de possibilidade para a elaboração da etnografia, ao menos no que toca à Escola Social Britânica. Por meio do caderno de campo, é possível 
descrever todas as atividades, mesmo as mais comezinhas, do grupo estudado. Condição básica para a descrição da totalidade social, já que todas as suas partes estão imbricadas umas nas outras. Todavia, o conteúdo do caderno de campo deve ser mantido no espaço externo ao do texto etnográfico, pois em seu interior ele seria inútil e disfuncional. Ele serviria como ponto de partida para a elaboração analítica, mediante a organização de seus dados e sua submissão a operações diversas (como, para seguir as trilhas de Malinowski, a elaboração de quadros sinóticos, a constituição de um corpus inscriptionum, para além da formulação etnográfica propriamente dita, cuja realização supõe atingirmos os imponderáveis da vida cotidiana).

A partir da década de 1960, o caderno de campo passa a invadir o texto etnográfico. Além, é claro, de começarem a ser publicados separadamente, seja como objeto de curiosidade, fonte de anedotário ou de escândalo. Desde então, sobe um clamor, proveniente sobretudo da antropologia americana, reivindicador da reforma no tratamento dado ao texto etnográfico. Dispensamo-nos, por exceder aos objetivos deste artigo, da apresentação de tais reivindicações e, com maior razão, de sua discussão. Para nosso proveito, bastará apenas a exposição sumária e esquemática de alguns de seus pressupostos básicos. ${ }^{3} \mathrm{O}$ movimento aparece como um sintoma da crise da representação que se propõe expor, ou seja, a respeito da descrição dos problemas concernentes a falar em nome de outro. Também como efeito da corrosão do sistema colonial, a destruição das colônias e a reconstrução de novos países que formariam o Terceiro Mundo a partir dessas ruínas. E, ainda, como efeito das novas formas de encarar a cultura. Os fatos culturais deixam de ser coisas expostas à observação e à coleta e passam a ser considerados invenções que se dão no diálogo: cultura como conjunto de símbolos, veículos capazes de habilitar a interpretação e a ação no mundo pelos indivíduos, tal como a definiu Geertz (1989[1973]). A propósito, alguns aspectos 
da obra de Geertz foram fundamentais aos trabalhos de certos membros do movimento, pese embora a crítica com que aquele autor não deixou de ser alvejado: a etnografia como esforço ou realização de uma "descrição densa", ou seja, de formular uma hierarquia estratificada de estruturas significantes. No campo, sugere Geertz (1989[1973], p. 23), nem se imita o nativo nem se vira nativo. Conversa-se com ele visando alargar o universo humano. O objetivo final da etnografia é a compreensão da cultura como conjunto de símbolos ou de signos interpretáveis. Mas tais descriçōes, vale lembrar, não são construções nativas, são construções dos antropólogos: são interpretações feitas a partir de interpretações, de segunda mão. São ficções, mas, como disse de si mesmo Jean Cocteau, daquelas que só falam a verdade.

Um deslocamento nas relações com a verdade, com a cultura, com a representação e com a subjetividade permitiu a formulação do que Clifford chamou de "debate político-epistemológico da descrição" e da representação do outro, centro nevrálgico da antropologia pós-moderna, que se pretendia inovadora em relação ao que chamaram de etnografia "moderna", sobre a qual recaíram todas as suas críticas. Como se presumiram inovadores, restava aos membros do movimento lançar seus morteiros sobre os pilares do edifício que bombardeavam. A observação participante foi o alvo primeiro. Ao passo que a subjetividade do autor migra ao protagonismo da cena, não está mais separada do referente objetivo do texto. A voz do autor, considerada apenas um acréscimo estético, torna-se presença obrigatória. A monofonia, que retira, seleciona, hierarquiza e unifica diversas vozes sob a voz ausente do autor, deverá ser substituída pelo artifício dialógico e polifônico. Não é permitido falar em nome de um outro homogeneizado (“os Nuer acreditam..."). ${ }^{4}$ É preciso ao mesmo tempo dar voz e reconstituir a heterogeneidade do discurso existente em campo ("dois Crow discordam..."). Uma vez que o autor é compreendido como um Eu-instrumento do conhecimento do outro, 
é preciso expor os efeitos subjetivos acarretados no etnógrafo na situação de campo. Efeito: inclusão da experiência de campo e auto-reflexividade.

Então, pode-se perguntar, enfim: na tentativa de retratar outras culturas, levando-se em conta a falha da referencialidade, é possível expressar uma verdade? Sim, mas apenas verdades parciais. Porque a etnografia é um estilo literário que por natureza é distorcido e limitado; portanto, não há esperança de etnografar objetivamente dada a determinação do contexto, a retórica etc.; as culturas são compósitos de inúmeras vozes, e a etnografia representa apenas poucas, quando não uma só; a cultura é cambiante, ao passo que a etnografia a fixa no tempo; enfim, além da crise de representação, há os problemas éticos das relações de poder entre nativos e antropólogos, o que comprometeria a tradução cultural e obrigaria, ao menos para Asad, a modificar a própria linguagem no processo de tradução ao invés de sacrificar o que é traduzido e ajustá-lo à linguagem do etnógrafo.

Finalmente, projeto que é, a antropologia pós-moderna é também propositiva (e não apenas imperativa): como a etnografia é inatingível, é preciso lançar mão de um estilo evocativo, pois, lembremos, a referencialidade não é confiável; como a experiência de campo é fragmentada, deve-se abrir mão do holismo e da sinédoque, conseqüentemente, pois as culturas não podem ser consideradas todos isolados.

Não é obra complicada demais elaborar críticas a esse conjunto de idéias, ao menos se o tomarmos como original. A idéia, por exemplo, que durante o trabalho de campo não encontraremos um conjunto coerente e unívoco de dados não passou despercebida a Malinowski, desde os Argonautas e talvez, sobretudo, em Coral Gardens. Para ele, "o contorno firme e claro da constituição tribal" assim como a tarefa de "formular inferências gerais", a partir de dados concretos obtidos com base em todos os dados observados (1978[1922], p. 24), são produtos finais do trabalho do etnógrafo, que tem por objeto não "fatos crus", mas 
"construções" operadas pelos nativos em foco, não obstante dispersas em diversos contextos da vida social (1935, p. 322, n. 2). Nessas condições, o etnógrafo não se coloca concebivelmente no exterior de seu texto etnográfico. No entanto, talvez seja mais rentável aproveitar o que o movimento pós-moderno trouxe de proveitoso, ao menos no âmbito de nossa pesquisa.

Se havia algo menos ortodoxo em nossas pesquisas, poderíamos talvez exprimi-lo como um descompromisso concernente à composição de um "todo coerente" a cabo do trabalho de investigação. Nunca tivemos propriamente um compromisso com uma verdade única. Assim como exposto nas introduções de ambos os livros, deixamos sempre clara a ênfase da perspectiva. Sabíamos que só veríamos o que nos fosse dado a ver, e que o mesmo valeria para os nossos colaboradores. Devido ao tema das pesquisas (violência e política - e o parentesco de permeio), conscientizamo-nos da inescapável parcialidade - em ambos os sentidos da palavra - à qual estaríamos condenados.

Porém, isso nunca redundou em um projeto de características mais experimentais, seja na fase de trabalho de campo, seja durante o desenvolvimento da etnografia. Reconhecemos, contudo, que o ambiente de discussões críticas da disciplina, que tantas vezes nos pareceu exceder-se em modismos e obediências, pode ter nos fornecido uma certa margem de manobra a que dificilmente recorreríamos se tivéssemos um "todo coerente" por objetivo primordial.

\section{O trabalho de campo no Vale do Pajeú}

Assim, se reconhecemos de bom grado o tanto devido ao solo intelectual de nossa formação, convém esclarecer quanto ao desenvolvimento de nossos trabalhos, como o "material de pesquisa" que gradativamente 
acumulávamos nos empurrou na mesma direção. Com esse intuito, uma descrição concernente às condiçõoes de realização de nossos trabalhos de campo será esclarecedora, de modo que nos renderemos, em certa medida, a um exercício de auto-reflexão. O propósito é explicitar o que esteve envolvido em algumas opções metodológicas importantes que tiveram de ser tomadas durante a efetuação do trabalho de campo e que redundaram, depois da etnografia produzida e publicada, em uma controvérsia cuja gestão guiou-se por princípios muito mais próximos do que distantes de nossa experiência de campo, a qual, dir-se-ia, não se encerrou com a produção etnográfica.

Realizamos a parte mais substancial de nossas pesquisas em certa fatia da mesorregião do sertão de Pernambuco, nas cercanias do rio Pajeú, tendo por temas centrais de investigação as brigas de família passadas e contemporâneas da região (Marques, 2002) e a constituição de grupos armados civis e militares lutando em causas diversas, durante a Primeira República (Villela, 2004). Em princípio recorreríamos a métodos diversos de realização das pesquisas, servindo-nos principalmente do trabalho de campo em moldes mais ortodoxos no primeiro caso e, na outra pesquisa, a documentos de arquivos públicos e dos fóruns das comarcas do interior. Mas, de fato, as notícias de jornais na capital e os processoscrimes arquivados naquelas comarcas se fizeram dados fundamentais, sobretudo em período inicial da primeira pesquisa, enquanto o trabalho de campo em sentido mais estrito ganhou importância cada vez maior na realização da segunda. Embora independentes, os dois trabalhos são complementares em larga medida. Mas, para efeito da presente discussão, o trabalho de campo relacionado às brigas de família é que estará sob enfoque, conforme foi concebido e realizado.

Um mês de trabalho de campo transcorrera antes da primeira notícia concreta de uma briga de família plenamente desenvolvida. Até então, 
ouvíramos diversos relatos sobre conflitos com morte e até vingança, mas nada que excedesse a esses dois atos. Sobretudo, nada que fosse narrado em primeira pessoa, com o envolvimento pessoal almejado. Até esse momento, o trabalho de campo se resumia, fundamentalmente, às conversas com camponeses em visita ao Sindicato dos Trabalhadores Rurais de Monte Verde e a levantamentos em processos nos fóruns. Essa pesquisa parecia deter-se no exame das relações no interior dos sítios, às custas da dura conquista da confiança dos que por ali passavam. ${ }^{5} \mathrm{De}$ súbito, os rumos foram alterados com uma notícia vinda da cidade de Monsanto (cerca de 30 quilômetros de Monte Verde): um júri inocentara naquela manhã um réu envolvido em briga de família e, para esse efeito, se empenhara pessoalmente um afim dele, homem respeitado na cidade. Por meio da rede de relacionamentos pessoais e de pesquisa que iniciávamos, Jorge chegara a este último homem, que, com sua esposa, se dispôs a conversar longamente sobre a questão $0^{6}$ que vivera a família dela. Promessa feita e cumprida, o tema acalentado, mas até então improvável de uma das pesquisas, ressurgira com força total. Porém, desde o dia dessa conversa, ficara claro que, se se quisesse como meta narrativas comprometidas desses fenômenos, para com elas lograr obter detalhes e significados inatingíveis por meio de relatos mais neutros, ${ }^{7}$ a renúncia de obter impressões similarmente intensas por parte dos opositores seria praticamente inevitável. Em outras palavras, soubemos de imediato que não seria recomendável, ou talvez possível, nem muito menos rentável do ponto de vista metodológico, procurar os inimigos de nossos interlocutores para uma conversa semelhante. Razões de ordem prática se acumulavam. Naquele caso, os inimigos em questão haviam abandonado a cidade, mas essa seria uma dificuldade superável se houvesse empenho bastante, dado que o destino deles era publicamente conhecido. Além do mais, parentes tão próximos deles, quanto esses que entrevistamos eram em relação ao núcleo de participantes da 
briga, continuavam residindo em Monsanto. Mas como procurá-los sem despertar suspeitas acerca de nossas intenções e do eventual interesse de nossos primeiros interlocutores? Como não magoar nossos interlocutores iniciais conversando com seus desafetos, pessoas a quem devotavam tanto ódio e ressentimento. Sabemos, por exemplo, que amizades são reforçadas pelo endosso ao ódio que um grupo alimenta por outros. Sabemos, também, que alguns, na esperança de não ferir suscetibilidades entre grupos intrigados, abrem mão de visitar ou receber pessoas ligadas diretamente a um lado da contenda. ${ }^{8}$ Esse conhecimento adquirido ao longo do trabalho de campo confirmou uma decisão a princípio intuitivamente tomada.

Às primeiras inquietações não tardou se acrescentar uma outra: até que ponto trazer à tona a memória desses episódios, por meio daqueles que neles de alguma forma intervieram, não faria aflorar ressentimentos que levaram as relações ao ponto de ebulição em algum momento de um passado mais ou menos recente? De modo agudamente perceptível, os protagonistas desses episódios não são meros objetos de conservação de um conhecimento inerme, transmissível conforme o maior ou menor talento para expressá-los verbalmente. Sua condição de agentes fazse notar, independentemente da condescendência ou sensibilidade sociopolítica dos investigadores, pelos riscos sugeridos pela própria natureza desse conhecimento transmitido. Suspeitas que só se reforçaram com o decorrer do trabalho de campo.

Assim como a grande parte dos descendentes do ancestral comum dos Santana' (sobretudo de um de seus netos), e exatamente por essa razão, o trabalho de campo estendeu-se por três municípios sertanejos, além do Recife. Mas, durante o período de campo e em todas exceto uma das etapas que se seguiram aos seis primeiros meses, nossa base de instalação foi em Monte Verde, município cuja população excede escassamente os 15 mil habitantes, dos quais pouco mais de 6 mil moram na 
sede. Por conseguinte, percebemos muito rapidamente que, além de não passarmos despercebidos, nos fizemos alvo da curiosidade, senão de investigação, tanto quanto fazíamos de nossos vizinhos. Nossos interesses e nossas condutas eram de sua conta. Assim, se viver como um nativo nunca foi um de nossos propósitos, o fato é que, em paralelo ao processo de compreensão de seus processos de apreensão e classificação do mundo, incorporamos vários desses signos de modo a oferecer, de volta, elementos com que nos pudessem em alguma medida apreender e classificar nos próprios termos. Nossa observação participante não se traduziu em nos transformar em nativos, mas talvez, mais do que para qualquer membro daquela comunidade - visto que éramos estrangeiros, ao passo que os nativos pertenciam, à partida, a uma família, senão a uma rede, que em parte lhe é transmitida por nascimento -, o lugar que nela ocupávamos dependia em grande medida da reputação que conquistássemos, portanto de nossa self-presentation e da leitura pública que dela fosse feita, ao passo que disso dependia o que nos seria apresentado e dado a conhecer de sua vida social. ${ }^{10}$ Certamente esse processo não foi vivido integralmente de forma consciente e nele interveio muita casualidade, e mesmo o teor de consciência nele envolvido não seria possível entender em termos de artificialismo. Como notou Jenkins (1994), o processo de apresentação de si e o de conhecimento do outro muitas vezes se confunde, e o trabalho de campo se constitui em muito do mesmo que se vive na vida social.

Por mútua empatia, por busca de socialização tanto em sentido pessoal quanto em proveito da pesquisa, estabelecemos e fortalecemos laços de amizade com uma porção da família Santana, principalmente com algumas irmandades (grupos de siblings) originárias de uma fazenda localizada na divisa entre os municípios de Jordânia e Monsanto. ${ }^{11}$ Isso não significa que em um passe de mágica passamos a compartilhar de uma mesma rede de amizade e ajuda mútua. Se focalizarmos seus integrantes, 
as redes têm sempre uma porção comum a outras redes e uma parte que se tece individualmente. Os membros da família Santana da fazenda Imbuzeiro nos integraram em suas redes, abrindo-nos nelas portas fundamentais de acesso às nossas pesquisas; e não foi à toa que por intermédio de um deles chegamos ao primeiro relato de uma briga de família em que eram mencionados motivos, anseios e emoções. Os Santana do Imbuzeiro não foram autores de narrativas, na mesma condição, de nenhuma outra questão de família além daquela primeira. Mas por intermédio deles, ou de nossa relação com eles explicitamente mencionada ou implicitamente reconhecida, chegamos a outros narradores com diferentes graus de envolvimento em suas narrativas. Abrir e manter essas portas abertas foi sem dúvida o maior desafio da pesquisa - porém, esse dom levou consigo o respeito por outras passagens que deveriam se manter fechadas. $\mathrm{Ou}$, antes, essas outras portas não obrigatoriamente se fechavam. O respeito que deveria ser mantido era sobre o que se via do outro lado do umbral, na mesma proporção em que as portas se escancaravam.

Portanto, percebemos ou adivinhamos que a intensidade de nossas relações no campo estava ligada à densidade das descrições que procurávamos e seríamos capazes de reproduzir e, sobretudo, que simplesmente seria pouco recomendável buscar reproduzir a intensidade dessas relações entre antagonistas. Não se entenda que esses tecem redes absolutamente diversas entre si. Ao contrário, também os inimigos compartilham entre si muitas de suas relaçôes pessoais, familiares, políticas. Exatamente por isso, essas relaçóes precisam ser cuidadosamente cultivadas, principalmente através daquilo que se diz, daquilo que se exibe a respeito de si mesmo e dos outros com quem alguém se relaciona. Conforme nos disseram certa vez, para manter as relaçóes em bons termos ou para não agravar as condições em que se vive em meio a uma questão de familia, é necessário resguardo de boca. ${ }^{12} \mathrm{Um}$ dos principais signos de um sistema de demonstração de respeito é o silêncio. Mesmo quando 
uma briga de família entra em fase de arrefecimento, quando a troca de hostilidades fica suspensa, a relação de conflito não cessa, mas converte seus termos para um estado de intriga, caracterizado por um conjunto de evitações e preservação das distâncias que mantêm um conflito em latência. E intriga é coisa que não se acaba. Por isso, mesmo com o correr dos anos, quando antigos intrigados ou seus descendentes já esboçam reaproximaçóes, o assunto da briga deve ser ciosamente resguardado, como se sua mera menção fosse capaz de reacender a chama da questão. No momento em que um de nós perguntou dos detalhes de uma questão ocorrida 50 anos antes a uma senhora que trabalhou desde a sua infância na casa de uma família, ela se negou a responder. Instada pelo filho da patroa a fazê-lo, por se tratar de uma pesquisa, ela retrucou: "E a pesquisa é de fuxico?”. A respeito da mesma questão, um descendente de um participante direto, ao descobrir que o tema da conversa eram as mortes ocorridas no passado, levantou-se bruscamente declarando que hoje é amigo dos Cajado. E que, se falasse quem fora o autor da morte de um antepassado deles, estaria revelando um segredo que deveria permanecer desconhecido. E, sobretudo, que não é preciso relembrar fatos que devem, sim, ser esquecidos. O conteúdo e a forma de transmissão de certo conhecimento são objetos de restrição, sob pena de serem encarados como desafio e desencadear respostas. Assim, os planos da fofoca e do segredo são os únicos em que concebivelmente tais informações circulam.

Os objetivos da pesquisa sobre briga de família, muito conscientemente colocados, não eram exatamente o de conceber um sistema de vinganças constituindo um todo coerente dotado de certas regras. Eram antes os de compreender o funcionamento de certas formas de relaçóes de conflito, que de algum modo se reproduzem naquele universo social, segundo sugere o relato de Koster (1942) e Thebergue, desde fins do século XVIII, época de sua ocupação colonial. O levantamento docu- 
Ana C. Marques \& Jorge M. Villela. O que se diz, o que se Escreve

mental relativo a fins do século XIX e primeira metade do XX dá indicação na mesma direção. Nossos interesses pela perpetuação desses conflitos vindicativos nunca se traduziram na busca de eventuais deficiências nas instituições do Estado ou de alguma forma de anacronismo como causa do fenômeno. As questôes de família são estruturas de longa duração que merecem ser compreendidas em seus diversos sentidos sociais. $\mathrm{O}$ interesse da pesquisa situava-se no modo como esses processos de conflitos eram apreendidos por seus participantes de qualquer grau de envolvimento - o público, ficaria cada vez mais claro, com a análise dos dados, não deve ser entendido como externo ou transcendente, e cabia averiguar seu modo de intervenção. Assim, em vez da função de tais conflitos, propunha-se desvendar seu funcionamento e compreender tanto quanto possível tudo que é acionado, no que tange a relações e instituições ao longo desses processos. Apreensão que se buscava não através da visão do todo, do sistema, mas através das partes. As perguntas que a investigação procurava responder eram em torno de como os indivíduos e a coletividade agiam e pensavam nas brigas de famílias - o que, quando, por que, por quem fazer ou deixar de fazer alguma coisa concernente à briga; que valor esses atos continham e emprestavam a seus sujeitos? Desse modo, a pesquisa instrumentalizou, em concordância com seus objetivos peculiares, elementos de uma crítica metodológica que procura enfatizar a dependência dos dados em função dos meios empregados e das contingências própria das interaçôes sociais das quais também o pesquisador faz parte (cf. Herzfld \& Fernandez, 1998, p. 93).

A emergência de uma questão mobiliza profundamente uma comunidade, cujos membros se vêem implicados de diferentes formas. Estas, contudo, não são previsíveis nem antecipáveis. Ao contrário do que se relata sobre outros sistemas de vingança (cf. Peters, 1967; Verdier, 1980; Abu-Lughod, 1986; Black-Michaud, 1973), e não obstante as pressões sofridas pelos parentes mais próximos da vítima de uma ofensa, não há 
Revista de Antropologia, São Paulo, USP, 2005, v. 48 No 1.

uma obrigação irresistível que defina o autor da vingança. Sem dúvida, um irmão, filho ou pai é um primeiro candidato à sua realização e sobre quem recaem as primeiras suspeitas e as mais precoces acusações de uma morte vindicativa. Porém, sobretudo, quanto mais prestigiosa for sua família, maior o círculo de apoiantes que ela atrairá, e no seio dele se esfacelará a identidade individual do autor da vingança. Disso resulta, de um lado, que muita gente de diferentes graus de parentesco ou sem qualquer ligação desse tipo pode estar envolvida; de outro, que toda aproximação aos que sofrem e infligem ofensas corre o risco de ser interpretada como adesão ao lado em questão. Por isso, as posições que se pretende assumir nesses processos precisam ser exibidas, dadas ao público.

Quando nos foi dado presenciar - embora sem testemunhar visualmente - um episódio de uma questão, constatamos o cuidado dos presentes em acorrerem aos enterros das vítimas de ambos os lados do conflito, porque em casos como esse não se pode ser neutro, ao menos se pode apelar à isenção. Se naquela manhã festiva todos eram uma só e unida família, à tarde, após o tiroteio na rua principal da pequena sede distrital, os dois grupos de irmãos e de seus respectivos pais já eram cuidadosamente isolados, e a relação que se tinha com eles bem menos visceral do que parecera antes - ligações de compadrio e consideração, não realmente de sangue. Com isso, não insinuamos uma atitude covarde da parte dos convivas, nem mentirosa. Na verdade, notamos nesse e em outros episódios como essas atitudes são dispositivos que detêm o alastramento e descontrole dos rumos desses conflitos, que costumam ser muito custosos física, material e emocionalmente para uma coletividade bem mais numerosa do que o grupo que toma parte nas ações de ofensa e vingança.

Em situações em que a questão se alastra, ela funciona como um ímã que atrai para si um número indeterminado de grupos que estabeleceram previamente relaçóes com uma das partes contendoras e, por isso, podem ser instados tacitamente ou não a participar da briga que vêem 
Ana C. Marques \& Jorge M. Villela. O que se diz, o que se Escreve

na questão alheia um meio de aliar-se a uma das partes visando angariar meios tangíveis e intangíveis para as próprias querelas - ou para ganhar dinheiro, ou ambos. Lampião e seus irmãos, por exemplo, que aderiram a um grupo armado importante para combater um inimigo particular. Tal como fizeram tantos, juntando-se a bandos maiores e melhor aparelhados, com armas e relaçôes políticas, como os de Antonio Silvino, o de Sebastião Pereira e os de outros cangaceiros como Silvino Ayres de Albuquerque, Cassimiro Honório, José de Souza, Antonio Precipício, Zé Cipriano, Cincinato de Carvalho etc., de enorme celebridade local, mas cujas famas não lograram transbordar as fronteiras regionais (Villela, 2004, p. 210 e ss) - coisa que não tardou a suceder a Lampião e seu bando, que passaram a exercer inusitado poder de atração sobre sertanejos por qualquer motivo lançados na ilegalidade.

Nossa condição estrangeira não nos isenta da avaliação de nossos atos numa sociedade em que se tem por hábito lidar com forasteiros e situálos de alguma forma na comunidade. Forasteiros podem vir em fuga ou em busca de algum propósito menos lícito; para assumir algum posto administrativo, religioso ou judicial; para o desempenho de uma função técnica com mão de obra que se supõe indisponível ali, por exemplo. O grau de sua integração dependerá, talvez, mais dele mesmo do que dos nativos. Juízes, promotores e advogados, embora não obrigatoriamente, costumam levar uma vida "reservada", evitando oferecer aos residentes da comarca muitos signos com que classificá-los socialmente e, sobretudo, estabelecer vínculos que obstruam o livre curso de seus deveres. Mas o risco de, nos termos de Malinowski, "descer da varanda" (Stocking, 1992), local que para uns era condição de necessária neutralidade, para nós, era a cegueira em torno do que se precisava ver. E note-se que a cegueira, que para a Justiça é um princípio, não constitui necessariamente uma virtude, mas, talvez, a razão central de sua ine- 
ficiência, no que toca ao fenômeno em causa, desde o ponto de vista que era de nosso interesse apreender.

Estabelecer vínculos pessoais com nativos foi algo que aconteceu em ritmo e condições, diríamos, descontraídas, e se nada fizemos para criálos à força, tampouco nos dedicamos a impedi-los. Certamente percebemos que nossas aproximaçôes foram um meio valioso de obtenção de informação, de que não nos dispusemos a abrir mão. Mas elas não foram objetivamente planejadas, nem revestimos de disfarce nossa condição de pesquisadores ou nossos interesses de pesquisa que, ao contrário, tendiam a ser mais detalhadamente revelados na proporção do estreitamento dos vínculos que, por sua vez, refinavam o teor das declaraçôes.

Não queremos sugerir aqui uma desqualificação das teses que apontam a relação de autoridade envolvida no trabalho antropológico. Mas convém ressaltar, como outros de alguma forma já fizeram, que os termos das relações de poder estabelecidas nessa prática não são sempre os mesmos, nem devem ser unívocos. Sheehan (1993) explicitou constrangimentos consideráveis na definição do que e em que condições poderia ser publicado como resultado de sua pesquisa sobre a relação entre intelectuais e poder político na Irlanda. Entrevistar, na condição de uma jovem pesquisadora, políticos da cúpula nacional, aliados, amigos, parentes, amantes ou inimigos deles pode inverter a polaridade de autoridade que nas situaçôes coloniais demonstrou-se cabalmente investida no antropólogo. Além disso, cremos ser fruto de um certo preconceito imaginar que exercemos poder e autoridade entre nossos colaboradores, porque somos pesquisadores oriundos de uma universidade do Sudeste em meio a sertanejos nordestinos. Embora nos tenham sido sempre respeitosos, muitos deles convivem (ou são parentes) com pessoas cujo status é, para dizer o mínimo, bastante superior ao nosso e muito melhor avaliado localmente. Não é uma atitude propriamente antropológi- 
ca atribuir aos outros avaliaçôes que são próprias de nós mesmos. Afinal, uma frase que deveria aparecer como uma marca d'água (ou como uma assombração) em cada página escrita por todos os antropólogos é aquela que aparece num filme de Michelangelo Antonioni: a pergunta que você me faz me habilita a compreender melhor a sua sociedade do que a resposta que eu poderia dar a ela lhe habilitaria a compreender a minha. $\mathrm{Ou}$, como formula Herzfeld, se pretendemos fazer uma defesa razoável da etnografia, devemos estar prontos a assumir que uma análise acadêmica diagnostica tanto a visão de mundo do autor (sua cosmologia ou ideologia) quanto a fofoca e as práticas cotidianas dos nativos revelam as deles (1997, p. 101).

Assim, ao lado das observâncias da ética, a decisão entre o que publicar ou calar pode ter a ver com o reconhecimento de relações de poder envolvidas, na relação entre nativo e antropólogo, mas também dos nativos entre si, na generalidade dos trabalhos da disciplina. Poder ou autoridade não se concentram em apenas um lado da balança, presumivelmente mesmo nas pesquisas que envolvem grupos alijados do mando econômico ou político.

No caso dessa pesquisa sobre brigas de famílias, vários de seus informantes ou personagens são mais do que razoavelmente favorecidos do ponto de vista econômico, político e intelectual. E tal condição social se traduziu, na relação de pesquisa, em uma interlocução bastante equilibrada, no que se refere às relações de poder entre pesquisadores e informantes. Desse modo, muito do que dissemos sobre essas pessoas, dissemos com eles, mais do que deles ou por eles. A condição de pesquisador não nos investe de poder de julgamento nem obriga esses interlocutores a confissões, verdadeiras ou falsas. A duração e a natureza do trabalho de investigação que fazíamos também devem ter contribuído para nos distinguir de tantos jornalistas, que costumam fazer passagens fugazes ali para coletarem informações para suas matérias sobre violência no in- 
terior, desconsiderando, algumas vezes, o anonimato, a segurança e a moral das pessoas ao produzirem uma matéria que estampa "a verdade" desvendada pela argúcia do jornalista. Numa depuração das "ilusōes" nas quais estão imersos os locais, a "verdade" do jornalista opõe-se tanto ao "engano" local, "ignorante" e "atrasado", quanto à vilania dos poderosos que escondem sob o idioma da família a realidade submersa do crime. ${ }^{13}$ Mais concentradas nas motivaçôes do que nos fatos, nossas conversas pareceram se transformar, algumas vezes, em ocasióes únicas para que nossos colaboradores exprimissem impressões, opiniões, dúvidas, ressentimentos, frustrações, satisfações, emoções de várias ordens.

A tendência em privilegiar uma abordagem subjetiva do tema das brigas de famílias, sacrificando-se muitas vezes, durante as conversas, a busca de dados mais objetivos ou comprometedores, contribuiu para fazer do trabalho de campo uma experiência pessoal muito envolvente. Como foi dito, a condição de pesquisador nunca foi omitida nem esquecida, mas, efetuando-se de maneira muito informal, se misturou muitas vezes, para nós e para nossos interlocutores, com aquela de amigo. Mesmo, e provavelmente sobretudo, quando não portava gravador nem caderno de notas, o trabalho prosseguia, e em algumas ocasióes essa ambigüidade foi explicitada. Por mais descontraídas que fossem as circunstâncias, elas não estavam excluídas da pesquisa.

Mas isso não significa que para todos fosse suficientemente claro aquilo no que consistia "a pesquisa". ${ }^{14}$ Sabia-se que retornaríamos para casa e, ao longo do tempo, escreveríamos alguma coisa, um livro, a respeito. Como exatamente seriam esses livros, nenhum de nós, pesquisadores, sabíamos. Contudo, para nosso embaraço, prevalece naquelas cidades sertanejas uma idéia bastante convencional do que constitui um livro acerca daquelas comunidades. Durante o trabalho de campo, adquirimos diversos desses volumes constituídos da memória de uma comunidade, uma composição de genealogia das famílias mais prestigiosas 
do local com uma série de relatos, freqüentemente anedóticos, protagonizados por alguns dos indivíduos ali representados. Um livro como esse é uma espécie de celebração da comunidade ali retratada. Seus membros tornam-se personagens e ganham prestígio na proporção de sua participação. Mesmo ter apenas o nome impresso ali é motivo de orgulho, sinal de consideração, que tem como contraponto o ressentimento pelo fato de não ter sido mencionado. Essa a hipótese mais grave, pois não se usa esse tipo de meio para a difamação e a maledicência de pessoas ou de grupos familiares, pois essa seria uma incontornável declaração de guerra. Lembremos o que já foi dito a respeito da palavra entre os grupos que estudamos. Ela é, para usar a expressão de Favret-Saada, um fato empírico (Favret-Saada, 1977, p. 25). Lá, freqüentemente, assim como na feitiçaria em Bocage, "o ato é o verbo". ${ }^{15}$

Ao declararmos que de nossas pesquisas resultariam livros, percebemos que um modelo desse tipo de composição vinha à mente, alimentado, inclusive, pelas muitas perguntas que fazíamos em torno das relaçôes genealógicas e de afinidade. Por outro lado, as advertências de que mudaríamos os nomes de pessoas e localidades, no intuito de preservarlhes o anonimato - senão no interior da comunidade, que se revelou impossível, de qualquer forma fora dela -, foram várias vezes encaradas com indiferença e até relutância. Apesar disso, insistíamos em dizer que o faríamos, talvez como forma de evidenciar a natureza distinta do trabalho que realizávamos, por comparação ao modelo costumeiro.

Olhando retrospectivamente, parece inegável o quanto o trabalho de campo implicou mútua sedução entre pesquisadores e nativos. Tratouse, de um lado, de buscar as informaçōes mais reservadas possíveis, da conquista de guias que nos conduzissem aos bastidores. Mas também se tratou, de outro, de sermos persuadidos quanto a motivaçóes e justificativas morais em relação ao que se revelava. Assim, as brigas de famílias no interior de Pernambuco não eram retratadas como resultantes de um 
costume arraigado, uma execução irrefletida de um dever incontestável. Elas tendem antes a ser tratadas como males que não se conseguiu evitar, sobretudo porque não se controla os juízos individuais. Ao invés de processos orquestrados, elas costumam ser descritas como fruto do arrebatamento, sobretudo dos mais jovens. Essa imputação de responsabilidades a uma categoria de pessoas menos centrais na hierarquia de prestígio ajuda a manter outras pessoas isentas. As lideranças das famílias simplesmente não conseguiriam aplacar os ânimos insubordinados de seus parentes. Ao mesmo tempo, ainda que de algum ponto de vista seja reprovável, o conjunto das atitudes do lado com que se simpatiza ou no qual se toma parte - o caráter ou o grau da participação nem sempre foram claramente assumidos - encontra também justificativas morais. Essas ações são tratadas como respostas compreensíveis, de qualquer forma, a injúrias graves, cometidas por pessoas com motivações por sua vez consideradas desprezíveis. Os Gouveia "são chegados às armas", dizem os Santana; de outros grupos se diz serem dados ao roubo, segundo os Rossano; os Borges seriam predispostos a valentias. Seus antagonistas, proferindo tais juízos, costumam considerar-se a si mesmos pessoas de paz e trabalhadoras, porém dispostas a se defender à altura, sem fugir aos desafios. Mesmo as pessoas mais refratárias a todas essas ações - e elas são numerosas - raramente deixam de fazer julgamentos morais mais favoráveis em relação ao lado com que simpatizam, às custas da condenação da atitude inimiga. Para quase todos, senão todos, há em cada questão um lado melhor do que outro do ponto de vista moral. E essa não é uma mera conclusão com que se contentam em guardar para si. No mais das vezes, buscam nos convencer disso.

Ora, uma vez que consideramos tais justificativas morais um ingrediente essencial do fenômeno, e não dispositivos que encobrem realidades mais profundas, elas passaram de fato a fazer parte da análise sobre as brigas de família. A pesquisa, assim, resultou em uma etnografia que 
privilegiou a perspectiva das partes sobre o todo, no intuito de elucidar os significados envolvidos nesses fenômenos. Por todas as razões aludidas até aqui, o método empregado para a realização desses objetivos consistiu em explorar em profundidade o ponto de vista de um dos lados da questão, em detrimento de seus antagonistas. Para retomar Sluka, não ser neutro não implica ser partidário (1995, p. 288). E esse é um ponto fundamental: isso não redunda em uma tomada de posição dos pesquisadores nesses processos. Por mais intensa que seja a empatia entre pesquisadores e seus interlocutores (e muitas delas tornaram-se verdadeiramente intensas e sinceras), entre estrangeiros e nativos, nossas posições condicionam apreensões distintas, ainda que não obrigatoriamente neutras. Inclusive porque, em um fenômeno como o das brigas de família, uma atitude mais engajada parece simplesmente inadmissível. A dedicação em compreender tudo o que se passa em tais processos não se pode confundir com a sua apologia. Da mesma forma, a parcialidade explicitamente proferida com relação à apreensão do fenômeno não constitui adesão a uma causa.

\section{O discurso etnográfico e a leitura nativa}

Essa postura de pesquisa, embora pouco ortodoxa, poderá talvez ser mais facilmente assimilável na academia, mesmo que não isenta de críticas. Entre nativos, porém, ela revela-se consideravelmente mais problemática. E não pense que isso se deve ao alijamento dessas pessoas do circuito acadêmico, porque a principal controvérsia gerada pela etnografia das brigas de família envolveu justamente pessoas de elevada formação cultural. De todo modo, é perfeitamente compreensível que alguém nos tenha tomado como partidários de uma ou outra causa e se sinta, assim, injustiçado pelo modo como viu a si ou aos seus estampados na etno- 
grafia que se seguiu à pesquisa. Sua indignação e protesto ficaram explicitados em mensagem dirigida a um de nós.

Ao invés de explicar com isenção os "fenômenos" ligados à problemática das rivalidades familiares sertanejas, a senhora preferiu agradar a pessoas particulares, suas amigas, no que se refere a Jordânia. Fez descrições completamente tendenciosas de personalidades ligadas aos fatos, com teor completamente maniqueísta. Isso é deplorável e invalida qualquer tentativa de querer elevar algo a caráter científico.

A passagem sintetiza bastante bem seus argumentos que se reforçaram ao longo de suas duas ou três páginas. O grande motivador dos vários ataques à legitimidade da tese foi uma descrição que, na opinião do autor da mensagem, denegria a imagem de seu pai, na mesma medida em que exaltava injustificadamente as de outras pessoas.

Quanto à mancha que a senhora quis imputar à imagem de meu pai, eu me sinto tranqüilo, porque para os "acadêmicos" da "universidade" ela poderá até parecer verossímil mas, para as pessoas que o conheceram, nunca passará de um delírio de uma mente "enviesada", digamos assim. Você perdeu a oportunidade de analisar uma personalidade realmente "rara" e incrível, dessas que quase não existem mais. E olhe que, paradoxalmente, eu tenho a tranqüilidade de não estar fazendo essas declarações de forma passional ou emocional. Ele realmente ERA: alguém de uma simplicidade que podia beirar os limites do simplório, mas sem nunca chegar lá!!!!! Simplesmente porque, apesar de todos os desatinos que cometeu na vida, que, ao contrário de meu irmão, eu entendo e justifico, mas não vejo exatamente como motivo de orgulho, ele conseguia passar incólume, pairando sobre tudo, em nome de uma ética talvez meio quixotesca, mas em que realmente acreditava e fazia com que todos sentissem a sinceridade. Disso 
Ana C. Marques \& Jorge M. Villela. O que se diz, o que se Escreve

sim, eu me orgulho: como também de sua força, do respeito que inspirava e que fazia com que todas as questôes e os problemas das rivalidades familiares terminassem chegando às suas mãos para resolver - o que de certa forma evitou que conflitos aflorassem muito antes desses desencadeados mais recentemente.

O remetente tem razão em apontar a ausência de nuances em relação à figura de seu pai, quando outras pessoas retratadas na tese ganharam descrição muito mais detalhada. Com efeito, uma única e rápida menção foi feita a esse personagem. Nela, explicitou-se uma suspeita não confirmada, uma especulação a respeito de seu envolvimento indireto, embora crucial, em um dos episódios de uma questão. Suspeita que foi descrita enquanto tal e sem que fosse atribuída a nenhum informante. Mas, para o autor da mensagem, o que estava e o que não estava escrito na passagem eram de menor importância. A bem da verdade, ele chegou a declarar que nem sequer leu o livro, embora em um primeiro momento tenha se entusiasmado com a idéia.

(...) eu gostaria de esclarecer que não li o seu livro completo, nem pretendo fazê-lo, embora, de início, quando soube de seus propósitos por intermédio de meu irmão (...), imatura e insensatamente, tornei-me um entusiasta, a ponto de recomendá-lo à minha amiga (...), aí de São Paulo. Eu não precisei ler, porque as leituras que fizeram para mim, por telefone, (...) foram mais do que suficientes para chegar a todas essas conclusões e não querer mais perder tempo com o resto do teor.

Em meio a toda perturbadora crítica que o livro sofreu, essa declaração acrescentou-nos perplexidade. Constituiu-se, de algum modo, uma opinião sobre um trabalho afinal desconhecido ou parcialmente conhecido. Analogamente a Davis (1993) - que se dedicou a distribuir exem- 
plares de seu livro entre a comunidade pesquisada que o rejeitava sem conhecer -, a única forma de remediar essa situação que nos ocorreu foi opor o conteúdo de suas acusações a passagens do texto. Na correspondência com o crítico, reproduzimos passagens do livro em que constavam as ressalvas às opiniōes ali mencionadas, sinalizando seu caráter nãofactual; em segundo lugar, foi destacado que os personagens cuja descrição ele considerou "edulcorada", em outros momentos, no mesmo livro, foram objeto de descrições não interpretáveis como elogiosas. Tais descrições não tinham por proposta, obviamente, denegrir ou exaltar quem quer que fosse. Mesmo porque, e apesar de continuarmos avaliando sua crítica como consideravelmente passional malgrado sua opinião a respeito de si mesmo, entendemos que seu pai, entre outros vários personagens daquela etnografia, "ERAM" de fato extraordinários, capazes de levar sua disposição de ajudar e defender familiares e amigos, assim como suas posiçôes morais, até as últimas conseqüências. Em terceiro lugar, aspectos da opção teórica e metodológica da pesquisa foram explicitados, no intuito de justificar a presença de pontos de vista reconhecidamente parciais. De certa forma, considerações presentes na introdução do livro lhe foram repetidas. No texto publicado, elas se voltam para todos os leitores, mais ou menos instruídos na antropologia. $\mathrm{O}$ mesmo argumento devia ser dirigido, então, a esse leitor particularmente crítico, mais do que suficientemente instruído nas formas acadêmicas, e extremamente interessado.

Mas esse diálogo merece um tratamento menos defensivo do que nossa reação imediata suscitou, porque, ao longo do tempo, muitos outros inicialmente despercebidos foram se acrescentando, por meio da compreensão que o trabalho etnográfico proporcionou. Um deles foi muito prontamente levantado por Christine Chaves (comunicação pessoal), uma das poucas pessoas com quem essas afliçôes foram divididas no momento em que irromperam. Leitora atenta do texto publicado 
(Chaves, 2004) e com sensibilidade aguçada pela própria experiência como etnógrafa (Chaves, mimeo), ela logo percebeu que esteve muito menos em jogo o conteúdo do texto, o que ali era dito, do que o fato daquilo ter sido escrito. Apesar de os atributos associados aos personagens serem expressão de voz pública, embora sussurrante, sempre dissonante e jamais unânime, há circuitos e timbres em que tais expressões são aceitáveis e outros em que não são admissíveis. Uma coisa é ouvir e reproduzir um saber (observado ou suspeito, certo ou errado) no tom e para o público da fofoca, por exemplo. Outra coisa é exprimilo para o público que extravasa a fronteira da intimidade comunitária. Com efeito, o livro revela uma série de saberes e segredos públicos, que não deixam de ser segredos por serem públicos. Ademais, essa publicidade se deu na forma de um livro, à qual a comunidade empresta os significados já assinalados. Esse trânsito de significações locais e exóticas suscitadas pela publicação do livro se revela também quando percebemos que, se tomado como um produto da comunidade dos pesquisados e não dos pesquisadores, o livro fere regras importantes do convívio social. Mesmo sem qualquer contato com a autora durante a pesquisa, de cuja realização só tomaram conhecimento tardiamente, e apesar do evidente acesso a muitas outras formas de literatura, de algum modo por conta do tema, ou talvez pelo conhecimento da realização da pesquisa na comunidade, junto a pessoas conhecidas e prezadas, no intervalo que sucedeu o trabalho de campo e antecedeu a publicação do livro - gerou-se uma expectativa de história da comunidade para a comunidade, e essa expectativa foi traída. Se houve traição, contudo, além de involuntária, ela circunscreveu-se a uma expectativa que não alimentamos. Os segredos que nos foram confiados e que nos pareceram comprometedores não foram revelados. E se opiniōes, versões, argumentos ou motivações, assumidos ou imputados, foram divulgados - não fatos, insisti- 
mos -, as condições em que o foram, assim como o plano discursivo que o texto representa, não podem servir a propósitos de difamação.

Intuitivamente, chegamos a essa conclusão durante a troca de correspondência, na qual ressaltamos o quanto o livro se dirigia para um público que, ao contrário de sua comunidade, não decifraria os pseudônimos. De fato, soubemos o quanto outros leitores oriundos de nosso universo de pesquisa se dedicaram a decifrar as identidades por trás dos pseudônimos, mas também do quanto seu êxito e esforço estiveram restritos à própria comunidade. Para os residentes de Jordânia, personagens de Monte Verde e Monsanto permaneceram genericamente sob a penumbra, apesar do grande prestígio de que alguns se revestem. Esse cuidado que a nós figurou indispensável, dada a natureza do assunto abordado e seu potencial gerador de inconvenientes vindos não somente de dentro como de fora das comunidades, por vezes causou insatisfação naqueles que preferiam ter sua identidade mais exposta. Os leitores do livro experimentavam um gênero literário distinto, mas constituído de narrativas cujo conteúdo lhes era suficientemente familiar para potencializar prestígio ou detração àqueles ali mencionados. A opção pelos pseudônimos desagradou a ambos os possíveis beneficiários ou prejudicados, por excesso ou por insuficiência de zelo. Porém, constatadas as paixões desencadeadas pelas narrativas, a restrição do reconhecimento das reais identidades a uma comunidade consideravelmente localizada em algum grau parece hoje, ainda mais do que antes, uma medida necessária. Pois o uso dos pseudônimos preserva um anonimato "para fora" e, portanto, para um público teoricamente ilimitado, e, se sua eficácia está longe de ser absoluta, de qualquer modo restringe o reconhecimento pessoal ao interior da comunidade e só o revela de modo não imediato, mas por meio de um conjunto de relações pessoalmente reconhecido. Além disso, as insatisfações opostas geradas pelo uso 
do pseudônimo constituem, elas mesmas, um signo da natureza distinta desse texto em relação a outros produzidos por membros da comunidade. Provoca um estranhamento, explicita sua condição estrangeira, embora próxima, sugerindo uma forma de apropriação diferenciada, ainda que de alguma forma também já pré-codificada.

Toda essa ambigüidade foi geralmente muito bem assimilada pela generalidade dos leitores com os quais tivemos o privilégio de encontrar, apesar de o episódio focalizado ter demonstrado, para nosso desagrado, a inconveniência de uma intensa circulação interna à comunidade. Os leitores "nativos" tenderam a ver no livro os próprios retratos e os das pessoas que lhes são próximas. Retratos cujos detalhes, obtidos por meio das opiniōes divergentes colhidas na comunidade, tenderam a substituir com ambigüidade a superficialidade das descrições mais fugazes dispersas pelos distintos interlocutores dos pesquisadores. Viemos a constatar, agora para nosso alívio, que mesmo os mais fervorosos admiradores desses personagens, embora assumindo para si perspectivas mais monótonas a seu respeito e discordando das opiniōes divergentes, não se mostraram ofendidos com o que leram. A esse respeito, o fato de nos conhecerem pessoalmente parece ter interferido de modo definitivo na forma como assimilaram a leitura e decodificaram os significados estrangeiros do livro. Eles não o tomaram como instrumento de publicação (tanto no sentido de tornar público quanto no de levá-lo às prensas) de saberes e opinióes íntimos, como fez o crítico. Compreenderam que tais descrições de caracteres pessoais se compunham de impressóes dispersas pela sua comunidade e não da autora, e que, embora talvez não correspondesse bem ao que desejavam, aquele livro tinha propostas e se destinava a um universo de leitores largamente distinto daquele das obras de história da comunidade escritas em seu interior e, fundamentalmente, para o próprio público. 
Mais do que isso, e paradoxalmente, alguns dos poucos informantes, a que, pela proximidade e confiança que privamos, contamos o que se passou, re-situaram o episódio na "economia das trocas simbólicas locais". Para eles, a escolha do tema das brigas como foco não denegria a imagem nem da comunidade nem dos indivíduos em particular. Na verdade, percebemos que o livro é equivalente a um ato cometido no interior de uma comunidade, e, por isso, é sujeito às suas opiniôes, divergentes por natureza. E que essa divergência, assim como todas que dizem respeito às reputações coletivas e individuais, reflete a história das relaçôes concretas ali erigidas. Nossos atos, portanto, foram lidos por meio das relações que fomos capazes de tecer ali. Em suma, a experiência de campo ofereceu o meio de apreender de uma forma estrangeira saberes locais que, por sua vez, também se apropriaram com os significados próprios de produtos exóticos. Afinal, os significados dos textos escritos assim como de outros textos - não pertencem a seus autores. Por vezes, como vimos, tampouco a sua leitura.

Apesar de muito do que foi suscitado pelo texto resultar de uma apreensão estrangeira de versões - por certo localmente interessadas - tanto a crítica quanto a nossa defesa são reveladoras de nossa imersão no universo social investigado, de seus limites, mas também de sua profundidade. A condição de fora e de dentro muitas vezes se misturaram, se fizeram ambíguas. $\mathrm{O}$ teor da acusação sofrida não seria plausível para uma reportagem de jornal ou um relatório de investigação policial condiçōes exógenas o bastante para dispensarem disputas. Ele exigiu de nossa parte um diálogo, uma troca de pontos de vista, expressivos de distâncias bem menores. Também nos induziu a buscar formas convencionais de apaziguamento, como o recurso à mediação e a recusa à omissão de que sentimos necessidade. Percebemos, por meio desse episódio, a que poderíamos qualificar agonístico, quanto por meio dele buscamos 
fixar-nos uma reputação. Conflito e heterogeneidade são ingredientes decerto inerentes a todo campo social, de forma que se exclui a priori toda unanimidade de opiniōes a nosso respeito (ou a do que quer que seja). Mas, não obstante desagrados causados, acreditamos que por meio desse diálogo nem bem acadêmico nem bem nativo - e embora inspirado nas duas fontes - pudemos preservar e reiterar o duplo e por vezes difícil compromisso que nos dispomos assumir.

\section{Notas}

1 O uso do termo "nativo" foi alvo das críticas de Appadurai (1988), porque alude ao confinamento ao qual estariam condenadas as pessoas ou os grupos de pessoas que são os temas das pesquisas dos antropólogos. Esse confinamento pode ser de ordem espacial, moral e intelectual ou mesmo ecológico, todos os aspectos estando interconectados.

2 A esse respeito, por exemplo, ver autores distintos como Evans-Pritchard (1985[1952]), para quem o trabalho de campo faz parte da formação acadêmica de um antropólogo, e Geertz (1989[1973]), para quem a definição daquilo que faz um antropólogo passa necessariamente pelo trabalho de campo, por meio do qual é possível elaborar-se uma "descrição densa".

3 Embora a bibliografia resultante do movimento chamado "antropologia pósmoderna" da década de 1980, bem como de suas principais influências, teses, teorias (assim como o anedotário - justo ou injusto, hiperbólico ou realista - criado por seus detratores) seja sobejamente conhecida, não custa apresentar uma breve lista: seus principais manifestos coletivos, Writing Culture (Clifford \& Marcus, 1986) e Anthropology as Cultural Critique (Marcus \& Fisher, 1986), mas também alguns textos seminais, influentes e de recapitulação - Asad (1973), Clifford (1983), Rabinow (1988), Ortner (1995), Fisher (1999), Appadurai (1988a). Para uma síntese do movimento, ver Kuper (2002[1999]), e para um comentário crítico, Birth (1990). 
4 De resto, essa é uma das críticas que a noção de cultura vem recebendo há muitos anos. A esse respeito, contra a noção de cultura, ver Abu-Lughod (1991, p. 142, 153 e ss; 1993, p. 6 e ss); e, a favor, conferir Sahlins (1997) e Ortner (2005, p. 35 e ss).

5 A respeito do caráter mediatizado da antropologia que estuda a violência, ver Rodgers (2001, p. 1-2). Para esse autor, ao contrário do que ocorre com a maior parte das pesquisas antropológicas, as que se debruçam sobre o tema da violência limitam-se à realização de entrevistas e a metodologias não participativas, retrospectivas e externas ao contexto da violência. Não obstante essa crítica, admite ser dispensável o testemunho de atos violentos para a compreensão da violência

6 As palavras em itálico, salvo as em língua estrangeira, são termos nativos. As questôes devem ser lidas como formas peculiares de conflitos, que traduziremos aqui como as brigas entre grupos rivais identificados por um nome ou apelido estendido a um grupo familiar (que engloba também não-consangüíneos), que se perpetuam no tempo, resultando em atos violentos e recíprocos, e que adquirem diversas magnitudes a depender da potência e da capacidade de respostas das partes em conflito.

7 Sluka (1995, p. 287 e ss) recomenda vivamente que a pesquisa antropológica que envolva ou foque situações de violência ou antagonismo acentuado deve abrir mão de qualquer neutralidade em época de forte antagonismo.

8 Há casos em que é necessário fazer escolhas dramáticas e assumir posições constrangedoras, quando a questão ocorre entre grupos de parentes. Soubemos de relatos de quem deixou de ir ao sepultamento de um parente porque sua família era inimiga de outra, também parente.

9 Nomes próprios de pessoas, famílias e localidades foram modificados nos textos anteriores e neste artigo. Os Santana são o nome de uma família instalada há muitos séculos no município de Jordânia. Praticamente desde então é uma das principais referências políticas de lá.

10 Sobre as condições de efetuação de trabalho de campo em sintonia com o argumento de Goffman em The presentation of selfin everyday life, ver Berreman (1975).

11 Ao contrário de Monte Verde, localizado a mais de mil metros de altitude e que goza de clima mais ameno, dado a mais umidade (por isso chamado localmente de brejo), Jordânia e Monsanto (cerca de 25 mil e 70 mil habitantes, respectivamente; cerca de 15 mil e 49 mil habitantes nas sedes municipais, respectivamente) situam-se no que é classificado localmente como sertão. 
Ana C. Marques \& Jorge M. Villela. O que se diz, o que se Escreve

12 Resguardo de boca tem dois significados: um deles é meramente dieta. O outro é manter em silêncio o que não é para ser falado. Os grupos com os quais fizemos a pesquisa costumam ser graves em relação à palavra. De modo a considerarem "que a língua mata o corpo".

13 Não valeriam a pena citações (e elas são muitas), mas é prática comum ao jornalismo que cobriu as brigas de família na região reduzir ao plantio de maconha a rica pluralidade de motivaçôes que deu início e perpetuou a questão em Jordânia.

14 A Associação Americana de Antropologia pretende, desde 1971, que os antropólogos em trabalho de campo explicitem aos "informantes" os objetivos e a finalidade da pesquisa que fazem sobre eles. Isso seria interessante se a maior parte de nós, antropólogos, tivesse claro, para nós mesmos, os objetivos de nossas pesquisas assim que chegamos a campo.

15 Conferir, por exemplo, em Villela (2004) o número de vezes em que, antes de efetuar um ato violento, se desafia o ofensor oralmente por meio da seguinte fórmula: "Sustenta o que disse!". Ou seja, insta-se o verbalizador a transformar sua palavra em ato para que ela possa valer como fato empírico.

\section{Bibliografia}

ABU-LUGHOD, Lila

1986 Veiled Sentiment. Honor and Poetry in a Bedouin Society, Berkeley, University of California.

1991 "Writing Against Culture", in FOX, R. (org.), Recapturing anthropology. Working in the present, Santa Fe, School of American Research Press.

1993 Writing women's worlds. Bedouin stories, Berkeley, University of California Press.

APPADURAI, Arjun

1988a "Introduction: place and voice in anthropological theory", Cultural Anthropology, vol. 3(1): 16-20.

1988b "Putting hierarchy in its place", Cultural Anthropology, vol. 3(1): 36-49. 
Revista de Antropologia, São Paulo, USP, 2005, v. 48 No 1.

ASAD, Talal

1973

"Two European Images of non-european rule", in ASAD, T. (org.), Anthropology and the Colonial Encounter, Nova York, Humanities Press.

BLACK-MICHAUD

1973 Cohesive force. Feud in the mediterranean and middle east, Nova York, St. Martin's Press.

BERREMAN, Gerald

1975 "Etnografia e controle de impressões em uma aldeia do Himalaia", in ZALUAR, A. (org.), Desvendando máscaras sociais, Rio de Janeiro, Francisco Alves.

BIRTH, Kevin

1990 "Reading and writing ethnographies", American Ethnologist, vol. 17(3): 549-57.

CHAVES, Christine A.

2004 "Intrigas e questóes. Resenha", Mana, n. 10(2): 428-31.

s/d "Os limites do consentido", mimeo.

CLIFFORD, James

1983 "On ethnographic autority", Representations, n. 2: 118-46.

1986 "Introduction", in CLIFFORD, J. \& MARCUS, G. (orgs.), Writing culture.

The poetic and politics of ethnography, Berkeley, University of California Press.

CLIFFORD, J. \& MARCUS, G. (orgs.)

1986 Writing Culture. The Poetic and Politics of Ethnography, Berkeley, University of California Press.

DAVIS, Dona

1993 "Unintended Consequences: the mith of 'the Return' in anthropological fieldwork", in BRETTEL, C. (org.), When they read what we write. The politics of ethnography, Westport, Bergin and Garvey.

EVANS-PRITCHARD, Edwad E.

1985[1952] "Trabalho de campo e tradição empírica", in Antropologia Social, Lisboa, Edições 70 . 
Ana C. Marques \& Jorge M. Villela. O que se diz, o que SE Escreve

FAVRET-SAADA, Jeanne

1977 Les mots, la mort, les sorts, Paris, Gallimard.

FERNANDEZ, James \& HERZFELD, Michael

1998 "In Search of Meningful Methods". In: Handbook of Methods in Cultural Anthropology. Russel Bernard (org.), Walmut Creek, Altamira Press.

FISHER, Michael

1999 "Emergent forms of life: anthropologies of late or postmodernities", Annual Review of Anthropology, 28: 455-78.

GEERTZ, Clifford

1989[1973] "Uma descrição densa: por uma teoria interpretativa da cultura", in A interpretação das culturas, Rio de Janeiro, Guanabara Koogan.

HERZFELD, Michael

1997 Cultural Intimacy. Social and Poetics in the Nation-State. Nova Iorque, Routledge.

KOSTER, Henry

1942 Viagens ao Nordeste do Brasil. São Paulo, Editora Nacional.

KUPER, Adam

2002[1999] Cultura. A visão dos antropólogos, Bauru, Edusc.

JENKINS, Timoty

1994 "Fieldwork and the Perception of Everyday Life", Man, 29: 433-455.

MALINOWSKI, Bronislaw

1935 Coral gardens and their magic, Londres, George Allen and Unwin.

1978[1922] Os argonautas do Pacífico Ocidental. Relato do empreendimento e da aventura dos nativos nos arquipélagos da Nova Guiné, Melanésia, São Paulo, Abril.

MARCUS, G. \& FISHER, M.

1986 Anthropology as cultural critique. An experimental moment in the human sciences, Chicago, University of Chicago Press 
MARQUES, Ana Claudia

2002 Intrigas e questôes. Vingança de família e tramas sociais no sertão de Pernambuco, Rio de Janeiro, Relume-Dumará.

PETERS, Emrys

1967 "Some structural aspects of the Feud among the Camel-Hearding Bedouin of Cirenaica", Africa, 37.

ORTNER, Sherry

1995 "Resistence and the Problem of Ethnographic Refusal", Comparative Studies in Society anb History, vol. 37, n. 1.

2005

"Subjectivity and cultural critique", Anthropological Theory, vol. 5(1): 31-52.

RABINOW, Paul

1988 "Beyond ethnography: anthropology as nominalism", Cultural Anthropology, vol. 3(4): 355-64.

RODGERS, Dennis

2001 "Making Danger a Calling: anthropology, violence and the dilemas of participant observation”, Crisis States Program Working Papers, 6.

SAHLINS, Marshall

1997 "O 'pessimismo sentimental' e a experiência etnográfica: por que a cultura não é um 'objeto' em via de extinção", Mana, vol. 3(1) e (2): 41-74 e 103-50.

SHEEHAN, Elisabeth

1993 "The Student of Culture and the Ethnography of Irish Intelectuals", in BRETTEL, C. (org.), When they read what we write. The politics of ethnography, Westport, Bergin and Garvey.

SLUKA, Jeffrey 1995

"Reflections on Managing Danger in Fieldwork: dangerous anthropology in Belfast", in NORDSTROM, C. \& ROBBEN, A. C. (orgs.), Fieldwork underfire. Contemporary studies of violence and survival, Berkely, University of California Press. 
STOCKING JR., George Victorian anthropology, Nova York, Free Press.

1992 The ethnographer's magic and other essays in the history of anthropology, Madison, University of Wisconsin Press.

THEBERGE, Pedro F.

1973 Histórico sobre a Provincia do Ceará. Fortaleza, Editora Henriqueta Galeno.

VERDIER, Raymond

"Le système vindicatoire. Esquisse théorique", in VERDIER, R. (org.), La vengeance I. La vengeance dans les sociètés extra occidentales, Paris, Cujas.

VILLELA, Jorge L.

O Povo em armas. Violência e politica no sertão de Pernambuco, Rio de Janeiro, Relume Dumará.

ABSTRACT: In this paper, from certain negative reaction to the publication of an ethnography about family feuds in the hinterland of the River Pajeú (state of Pernambuco, Brazil), we propound an approach on reflexivity of the anthropological work inspired, theoretically, by the historicization of the place of fieldwork and ethnography inside the discipline and, empirically, through a retrospective sight of the specific conditions in which that research was made. The same case produced also pragmatic effects, which operated unexpected displacements in the relationship between researcher and subject of research. These displacements were perceptible, for instance, in the idiom used in the agonistic exchanges of accusation and defense; they also provided new perspectives regarding the conditions of sociability that we intended to describe.

KEY-WORDS: fieldwork, ethnography, reflexivity.

Aceito em setembro de 2005. 